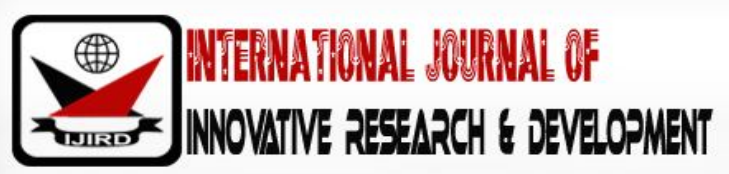

ISSN 2278 - 0211 (Online)

\section{Anti-Hypertensive and Anti-Oxidative Effect of Methanolic Extract of Vernonia Amygdalina (VA) in Tissue Samples of NaCL Induced Hypertensive Male Wistar Rats}

Onyema-Iloh OB
Chemical Pathology, Nnamdi Azikiwe University Teaching Hospital, Nnewi, Nigeria
Meludu SC
Basic Medical Sciences, Nnamdi Azikiwe University, Awka, Nigeria
Iloh EO
Industrial Chemistry, Chukwuemeka Odimegwu Ojukwu University, Uli, Anambra, Nigeria
Dioka CE
Chemical Pathology, Nnamdi Azikiwe University, Awka, Nigeria

\section{Abstract:}

Vernonia amygdalina (VA) is a medicinal plant cultivated in Nigeria and widely used as vegetables and in folk medicine in the treatment and prevention of many diseases like diabetes and hypertension. The aim of the study was to evaluate the antihypertensive and antioxidative effect of methanolic extract of VA in $8 \% \mathrm{NaCl}$ induced hypertensive male wistar rats. Forty wistar rats (120-160) g were assigned to 5 groups of eight rats each. Group 1,2,3,4 and 5 constitute the normal, hypertensive group, VA (200mg/ kg bwt) group, VA (400mg/ kg bwt) group and reference drug (lisinopril, 30mg/ kg/ 2mls/ day) group respectively. Group 3 and 4 were given the extract by gastric intubation for 4weeks after induction while group 5 was given the reference drug. All groups except group 1 were induced with $8 \% \mathrm{NaCl}$ for 0 - 4weeks before treatment with VA and reference drug for 4 -8weeks. VA significantly $(\mathrm{p} \varangle 0.05)$ reduced blood pressure, heart rate and blood volume after 4 weeks induction in group 3 and 4 in a dose dependent manner. The tissue lipid peroxidation product (MDA) was significantly $(p<0.05)$ reduced and the tissue antioxidant enzymes activities (SOD, CAT and GST) were significantly $(p<0.05)$ increased in VA extract group but not in lisinopril group. The result of the study suggests that VA possess antihypertensive effect against $\mathrm{NaCl}$-induced hypertension with additional antioxidative properties that may help in ameroliating the effect of oxidative stress in hypertensive condition.

Keywords: Vernonia amygdalina(VA), $\mathrm{NaCl}$ induced hypertension, Malondialdehyde(MDA), Catalase(CAT), superoxide dismutase ( SOD), gluthione -S-Transfrase(GST)

\section{Introduction}

According to WHO, as of 2014, approximately one billion adults of the population of the world have hypertension. Hypertension also known as high blood pressure is a long -term medical condition in which the blood in the arteries is persistently elevated (Naish 2014). It is actually when systolic and diastolic blood pressure reading is at or above 140/90 $\mathrm{mm} / \mathrm{Hg}$ (Poulter et al., 2015). High blood pressure using does not cause symptoms (CDC, 2015). But long term high blood pressure is a major risk factor for coronary artery disease, stroke, heart failure, atrial fibrillation, peripheral vascular disease, vision loss, chronic kidney disease and dementia (lackland and weber 2015; Lau et al., 2017).

High blood pressure is classified as primary (essential) and secondary high blood pressure. Primary high blood pressure makes up to $90-95 \%$ of the individual with hypertension while secondary high blood pressure makes up to 5-10\% of the individual with hypertension (poulter et al., 2015). life style factors that increase the risk include excessive salt in the diet, excess body weight, smoking and alcohol use (CDC, 2015; Poulter et al., 2015). The remaining 5-10\% of cases are classified as secondary high blood pressure with identifiable cause such as chronic kidney disease, narrowing of the kidney arteries, and endocrine disorder, or the use of birth control pills (Poulter et al., 2015). Lifestyle changes such as decreased salt intake, physical exercise, healthy diet, weight loss and also medications can lower blood pressure and decrease the risk of health complications (National heart, lung, and blood institute, 2015). Hypertension is more frequent in men, in those of low socioeconomic status and it becomes more common with age (Carretero, 2000). Vernonia amygdalina (VA) is a medicinal plant 
cultivated in Nigeria and widely used as vegetables and in folk medicine in the treatment and prevention of many diseases like diabetes and hypertension. A substantial body of evidence strongly supports the concept that lifestyle modification can have powerful effects on blood pressure. Increased physical activity (aerobic exercise) (Dimeo et al., 2012; Pescatello et al., 2015), a reduced salt intake (He and Macgregory, 2007; Sung, 2014), weight loss (Hersh and Bray, 2008), moderation of alcohol intake, increased potassium intake ((Perez and Chang, 2014), and an overall healthy dietary pattern, termed the dietary approaches to stop hypertension (DASH) diet, effectively lower blood pressure (Mortre et al, 2001). The dash diet emphasizes fruits, vegetables, and low fat dairy products (Mortre et al, 2001).

Vernonia amygdalina popularly called bitter leaf is used in traditional medicine to treat fever, malaria, diarrhoea, dysentery and diabetes. They serve as laxatives and fertility inducer. They are commonly used as vegetable. Therefore, in this study, Vernonia amygdalina was investigated for its possible chemotherapeutics that may be useful in the management of hypertension.

\section{Materials and Methods}

\subsection{AIM/ Objectives}

To investigate the antihypertensive and antioxidant effect of Vernonia amygdalina in $\mathrm{NaCl}$ induced hypertensive male wistar rats through the assessment of antioxidant enzymes, SBP, DSP, Mean blood pressure, blood volume and heartrate.

\subsection{Methods}

\subsubsection{Methanolic Extraction of Experimental Leaves}

(Lolodi and Eriyamremu, 2013). The experimental leave was collected and authenticated. Fresh bitter leaves were airdried at room temperature. Air-dried leaves of the plant were milled into powder, the powdered leaves were weighed and macerated into methanol ( $100 \mathrm{~g}$ of the plant material to $300 \mathrm{ml}$ of methanol) for 5 days with occasional shaking to ensure sufficient extraction of the active component. The methanolic extract was filtered using No. 1 filter paper and filtrate (solvent) concentrated to dryness under reduced pressure at $60 \pm 10^{\circ} \mathrm{C}$ in a rotary evaporator. The resultant methanolic extract was weighed and used appropriately.

\subsection{Animal Procurement}

Forty male wistar rats (120 - $160 \mathrm{~g})$ obtained from university of Nigeria Nsukka were used for the research. The rats were allowed to acclimatize for 2 weeks during which they were fed ad-libitum with rat chow and clean water. The rat local restrainers were included in their different cages to prepare the rats for blood pressure measurement. The rats were maintained under good laboratory conditions at a temperature of $22 \pm 2{ }^{\circ} \mathrm{C}$, relative humidity of $50 \pm 5 \%$ and photoperiod of $12 \mathrm{hrs}$.

\subsection{Animal Groupings}

The animals were grouped into five different groups $(1,2,3,4,5)$ of eight rats in each group after their body weight measurement. Group I is the normal group and Group 2 is the hypertensive group. Group 3, 4 and 5 were the groups given $200 \mathrm{mg} / \mathrm{kgbwt}(\mathrm{VA}), 400 \mathrm{mg} / \mathrm{kg} / \mathrm{bwt}(\mathrm{VA})$ and the reference group (lisinopril) respectively. The extracts were given through oral gavage daily for 4 weeks after 4 weeks induction period.

\subsection{Determination of Blood Pressure Parameters}

An automated computerized non-invasive tail-cuff blood pressure monitor, the CODA II TM NIBP recording system (Kent Scientific Corporation, Connecticut, USA) was used to record the SBP, DBP, MAP, BV and HR in rats. Rats were placed in restraining holders with a nose cone to calm the animals. The restrainers were placed on a heating pad ( $32 \pm 20 \mathrm{C})$ to warm the rat's tail and maintain blood flow to the tail. Animals were placed in the restrainers for at least 5 mins before monitoring the blood pressure and average of three consistent readings were taken for each rat weekly.

\subsection{Biochemical Assays}

\subsubsection{Determination of SOD Activity}

SOD was assayed by colorimetric method of Misra and Fredovich, (1972).

\subsubsection{Principle}

The ability of superoxide dismutase to inhibit the auto oxidation of adrenaline at pH 10.2 makes this reaction a basis for the SOD assay. Superoxide anion $\left.\mathrm{O}_{2}\right)$ generated by the xanthine oxidase reaction is known to cause the oxidation of adrenaline to adrenochrome. The yield of adrenochrome produced per superoxide anion introduced increased with increasing $\mathrm{pH}$ and also with increasing concentration of adrenaline. These led to the proposal that auto oxidation of adrenaline proceeds 
by at least two distinct pathways, one of which is a free radical chain reaction involving superoxide radical and hence could be inhibited by SOD.

\subsubsection{Determination of Catalase Activity}

Catalase activity was determined by colorimetric method of Sinha, (1972).

\subsubsection{Principle}

This method is based on the fact that dichromate in acetic acid is reduced to chromic acetate when heated in the presence of $\mathrm{H}_{2} \mathrm{O}_{2}$ with the formation of perchromic acid as an unstable intermediate. The chromic acetate then produced is measured colorimetrically at 570 to $610 \mathrm{~nm}$. Since dichromate has no absorbance in this region, the presence of the compound in the assay mixture does not interfere at all with the colorimetric determination of chromic acetate. The catalase preparation is allowed to split $\mathrm{H}_{2} \mathrm{O}_{2}$ for different periods of time. The reaction was stopped by the addition of dichromate acetic acid mixture and the remaining $\mathrm{H}_{2} \mathrm{O}_{2}$ is determined by measuring chromic acetate colorimetrically after heating the reaction mixture.

\subsubsection{Determination of GST Activity}

GST activity was determined spectrophotometrically at $37^{\circ} \mathrm{C}$ as described by Habig et al., (1974).

\subsubsection{Principle}

Glutathione-s-transferase catalyses the conjugation of reduced glutathione with the aromatic substrate 1-chloro-2, 4dinitrobenzene to form a complex. The complex formed has a characteristic absorption at $340 \mathrm{~nm}$. The spectrophotometric readings are considered indicative of enzyme activity.

\subsubsection{Determination of MDA Level}

MDA level was determined by the colorimetric method of Gutteridge and Wilkins, (1982).

\subsubsection{Principle}

Malondialdehyde (MDA) is a product of lipid peroxidation. When heated with 2- thiobarbituric acid (TBA) under alkaline condition, it forms a pink coloured product, which has absorption maximum at $532 \mathrm{~nm}$. The intensity of colour generated is directly proportional to the concentration of MDA in the sample.

\subsection{Statistical Analysis}

All the data were expressed as mean \pm S.D. The differences among treatment groups were analyzed by T-test, one-way analysis of variance (ANOVA) and post-hoc test. Values of $\mathrm{p}<0.05$ were considered statistically significant.

\section{Results}

\begin{tabular}{|c|c|c|c|c|c|}
\hline Groups & Baseline & Week 2 & Week 4 & Week 6 & Week 8 \\
\hline 1(normal) & $81.00 \pm 11.23$ & $85.33 \pm 16.95$ & $81.00 \pm 11.21$ & $82.66 \pm 23.71$ & $81.00 \pm 11.21$ \\
\hline 2(hypertensive) & $83.50 \pm 10.32$ & $126.33 \pm 5.78^{*}$ & $162.33 \pm 6.12^{*}$ & $172.00 \pm 7.87^{*}$ & $190.17 \pm 5.49^{*}$ \\
\hline 3(200mg/ kgbwt)VA & $85.32 \pm 10.98$ & $139.16 \pm 6.96^{*}$ & $171.00 \pm 9.01^{*}$ & $141.50 \pm 6.41^{*}$ & $97.50 \pm 4.27 * \beta$ \\
\hline $4(400 \mathrm{mg}$ / kgbwt)VA & $82.66 \pm 11.20$ & $131.33 \pm 7.15^{*}$ & $180.50 \pm 9.03^{*}$ & $128.00 \pm 1.89^{*}$ & $87.17 \pm 9.60^{*} \beta$ \\
\hline 5(lisinopril) & $82.23 \pm 11.66$ & $134.33 \pm 7.28^{*}$ & $168.66 \pm 6.88^{*}$ & $131.66 \pm 8.50^{*}$ & $104.50 \pm 7.76^{*}$ \\
\hline
\end{tabular}

Table 1: Showing Mean \pm S.D of Systolic Blood Pressure of Nacl Induced Hypertensive Wistar Rats from 0-8weeks P-Value<0.05 Is Considered Statistically Significant

*=Shows Significant Difference in the Duration When Compared with Baseline $B=$ Shows Significant Difference within the Groups after Treatment with VA 


\begin{tabular}{|c|c|c|c|c|c|}
\hline Groups & Baseline & Week 2 & Week 4 & Week 6 & Week 8 \\
\hline 1(normal) & $60.66 \pm 11.91$ & $60.67 \pm 11.91$ & $60.67 \pm 11.91$ & $59.67 \pm 15.50$ & $60.67 \pm 11.91$ \\
\hline 2(hypertensive) & $64.50 \pm 7.09$ & $107.00 \pm 18.00^{*}$ & $124.66 \pm 16.35^{*}$ & $124.33 \pm 13.95^{*}$ & $132.83 \pm 10.92^{*}$ \\
\hline $3(200 \mathrm{mg} / \mathrm{kgbwt})$ VA & $63.80 \pm 9.57$ & $93.83 \pm 9.84^{*}$ & $124.67 \pm 16.35^{*}$ & $108.00 \pm 2.52^{* \beta}$ & $69.67 \pm 5.82^{*} \beta$ \\
\hline $4(400 \mathrm{mg} / \mathrm{kgbwt}) \mathrm{VA}$ & $52.33 \pm 11.70$ & $85.50 \pm 17.89^{*}$ & $127.66 \pm 13.41^{*}$ & $94.67 \pm 8.91^{*} \beta$ & $63.50 \pm 11.13^{*} \beta$ \\
\hline 5(lisinopril) & $52.67 \pm 19.35$ & $92.33 \pm 14.27^{*}$ & $119.67 \pm 15.87 *$ & $109.83 \pm 16.69^{*}$ & $74.66 \pm 4.63^{*}$ \\
\hline
\end{tabular}

Table 2: Showing Mean \pm S.D of Diastolic Blood Pressure of Nacl Induced Hypertensive

Wistar Rats from 0-8weeks P-Value $<0.05$ Is Considered Statistically Significant

*=Shows Significant Difference in the Duration When Compared with Baseline. ${ }^{B}=$ Shows

Significant Difference within the Groups after Treatment with VA

\begin{tabular}{|c|c|c|c|c|c|}
\hline Groups & Baseline & Week 2 & Week 4 & Week 6 & Week 8 \\
\hline 1(normal) & $67.33 \pm 11.07$ & $68.00 \pm 15.36$ & $67.33 \pm 11.39$ & $68.00 \pm 15.36$ & $67.33 \pm 11.39$ \\
\hline 2(hypertensive) & $66.67 \pm 10.07$ & $95.33 \pm 18.82^{*}$ & $137.33 \pm 10.36^{*}$ & $141.83 \pm 11.78^{*}$ & $151.50 \pm 5.05^{*}$ \\
\hline $3(200 \mathrm{mg} / \mathrm{kgbwt}) \mathrm{VA}$ & $69.67 \pm 10.07$ & $108.50 \pm 5.57^{*}$ & $139.68 \pm 11.74^{*}$ & $106.67 \pm 11.57^{*} \beta$ & $78.66 \pm 2.73^{*} \beta$ \\
\hline $4(400 \mathrm{mg} / \mathrm{kgbwt}) \mathrm{VA}$ & $68.83 \pm 11.17$ & $100.50 \pm 13.24^{*}$ & $135.33 \pm 9.85^{*}$ & $94.50 \pm 15.41^{*} \beta$ & $70.50 \pm 10.93^{*} \beta$ \\
\hline 5(lisinopril) & $66.33 \pm 19.07$ & $106.00 \pm 16.34^{*}$ & $135.00 \pm 11.97^{*}$ & $90.00 \pm 24.15^{*}$ & $84.33 \pm 4.76^{*}$ \\
\hline
\end{tabular}

Table 3: Showing Mean \pm S.D of Mean Blood Pressure of Nacl Induced Hypertensive

Wistar Rats from 0-8weeks P-Value $<0.05$ Is Considered Statistically Significant

*=Shows Significant Difference in the Duration When Compared With Baseline

${ }^{B}=$ Shows Significant Difference within the Groups after Treatment with VA

\begin{tabular}{|c|c|c|c|c|c|}
\hline Groups & Baseline & Week 2 & Week 4 & Week 6 & Week 8 \\
\hline 1(normal) & $363.00 \pm 20.06$ & $368.00 \pm 20.07$ & $378.00 \pm 23.26$ & $378.00 \pm 23.25$ & $366.33 \pm 7.71$ \\
\hline 2(hypertensive) & $361.33 \pm 47.48$ & $368.50 \pm 25.54^{*}$ & $406.17 \pm 69.43^{*}$ & $441.00 \pm 42.72^{*}$ & $467.83 \pm 36.13^{*}$ \\
\hline $3(200 \mathrm{mg} / \mathrm{kgbwt}) \mathrm{VA}$ & $363.33 \pm 29.74$ & $384.67 \pm 30.83^{*}$ & $394.50 \pm 32.61^{*}$ & $370.83 \pm 36.95^{*} \beta$ & $355.50 \pm 12.58^{*}$ \\
\hline $4(400 \mathrm{mg} / \mathrm{kgbwt}) V A$ & $365.50 \pm 62.85$ & $370.83 \pm 22.65^{*}$ & $467.83 \pm 36.95^{*}$ & $432.83 \pm 70.25^{*} \beta$ & $427.83 \pm 44.84^{*}$ \\
\hline 5(lisinopril) & $362.83 \pm 43.70$ & $379.00 \pm 23.35^{*}$ & $417.00 \pm 42.57^{*}$ & $428.17 \pm 28.11^{*}$ & $369.17 \pm 35.40$ \\
\hline
\end{tabular}

Table 4: Showing Mean \pm S.D of Heartrate of Nacl Induced Hypertensive Wistar

Rats from 0-8weeks P-Value $<0.05$ Is Considered Statistically Significant

$*=$ Shows Significant Difference in the Duration When Compared with Baseline

$B=$ Shows Significant Difference within the Groups after Treatment with VA

\begin{tabular}{|c|c|c|c|c|c|}
\hline Groups & Baseline & Week 2 & Week 4 & Week 6 & Week 8 \\
\hline 1(normal) & $20.17 \pm 3.66$ & $20.16 \pm 3.06$ & $20.50 \pm 2.58$ & $21.16 \pm 2.56$ & $20.50 \pm 2.17$ \\
\hline 2(hypertensive) & $26.83 \pm 5.98$ & $45.50 \pm 30.04^{*}$ & $63.17 \pm 19.41^{*}$ & $76.50 \pm 6.63^{*}$ & $76.83 \pm 6.42^{*}$ \\
\hline 3(200mg/ kgbwt)VA & $25.66 \pm 5.05$ & $43.33 \pm 12.55^{*}$ & $69.33 \pm 12.37^{*}$ & $65.00 \pm 4.28^{*} \beta$ & $38.83 \pm 5.23^{*} \beta$ \\
\hline $4(400 \mathrm{mg} / \mathrm{kgbwt}) \mathrm{VA}$ & $23.83 \pm 4.75$ & $50.00 \pm 28.70^{*}$ & $70.00 \pm 9.18^{*}$ & $67.00 \pm 14.62^{*}$ & $28.17 \pm 8.28^{*}$ \\
\hline 5(lisinopril) & $20.50 \pm 2.74$ & $56.17 \pm 8.68^{*}$ & $70.50 \pm 5.92^{*}$ & $62.83 \pm 4.49^{*}$ & $24.50 \pm 7.05^{*}$ \\
\hline
\end{tabular}

Table 5: Showing Mean \pm S.D of Blood Volume of Nacl Induced Hypertensive Wistar Rats from 0-8weeks

. P-Value $<0.05$ Is Considered Statistically Significant

*=Shows Significant Difference in the Duration When Compared with Baseline

$B=$ Shows Significant Difference within the Groups after Treatment with VA

\begin{tabular}{|c|c|c|c|c|}
\hline MDA(nmol/ l) & Liver & Kidney & Testes & Heart \\
\hline Group 1 & $0.63 \pm 0.01$ & $0.75 \pm 0.02$ & $0.62 \pm 0.11$ & $0.52 \pm 0.01$ \\
\hline Group 2 & $3.71 \pm 0.02^{*}$ & $4.41 \pm 0.01^{*}$ & $3.51 \pm 0.01^{*}$ & $3.37 \pm 0.22^{*}$ \\
\hline Group 3 & $2.14 \pm 0.02^{*}$ & $2.95 \pm 0.03^{*}$ & $2.44 \pm 0.02^{*}$ & $2.03 \pm 0.02^{*}$ \\
\hline Group 4 & $1.55 \pm 0.01^{*}$ & $1.53 \pm 0.01^{*}$ & $1.43 \pm 0.01^{*}$ & $0.63 \pm 0.01$ \\
\hline Group 7 & $3.71 \pm 0.08^{*}$ & $4.39 \pm 0.45^{*}$ & $3.47 \pm 0.08^{*}$ & $3.34 \pm 0.25^{*}$ \\
\hline Fvalue & 15144.280 & 18169.648 & 7225.307 & 475.257 \\
\hline Pvalue & 0.001 & 0.001 & 0.001 & 0.001 \\
\hline
\end{tabular}

Table 6: Showing Mean \pm S.D of Malondialdehyde of Tissue Samples from Liver,

Kidney, Testes and Heart of Nacl-Induced Hypertensive Male Wistar Rat for 0 - 8 Weeks

Key: MDA=Malondialdehyde. $P$-Value $<0.05$ Is Considered Statistically Significant

*=Shows Significant Difference When Compared With Group 1(Normal Group) 


\begin{tabular}{|c|c|c|c|c|}
\hline SOD & Liver & Kidney & Testes & Heart \\
\hline Group 1 & $11.45 \pm 0.11$ & $10.59 \pm 0.26$ & $9.48 \pm 0.14$ & $11.48 \pm 0.28$ \\
\hline Group 2 & $7.38 \pm 0.32^{*}$ & $7.33 \pm 0.23^{*}$ & $5.44 \pm 0.21^{*}$ & $6.58 \pm 0.27^{*}$ \\
\hline Group 3 & $12.58 \pm 0.14^{*}$ & $13.75 \pm 0.43^{*}$ & $12.43 \pm 0.26^{*}$ & $12.71 \pm 0.16^{*}$ \\
\hline Group 4 & $16.48 \pm 0.31^{*}$ & $15.50 \pm 0.21^{*}$ & $14.46 \pm 0.36^{*}$ & $14.35 \pm 0.20^{*}$ \\
\hline Group 5 & $9.56 \pm 0.16^{*}$ & $9.14 \pm 0.02^{*}$ & $8.12 \pm 0.02^{*}$ & $8.39 \pm 0.07^{*}$ \\
\hline Fvalue & 1034.230 & 1365.990 & 1094.157 & 1638.569 \\
\hline Pvalue & 0.001 & 0.001 & 0.001 & 0.001 \\
\hline
\end{tabular}

Table 7: Showing Mean \pm S.D of Superoxide Dismutase of Tissue Samples from Liver, Kidney, Testes and Heart of Nacl-Induced Hypertensive Male Wistar Rat for 0 - 8 Weeks

Key: SOD- Superoxide Dismutase. P - Value $<0.05$ Is Considered Statistically Significant $*=$ Shows Significant Difference When Compared with Group 1 (Normal Group)

\begin{tabular}{|c|c|c|c|c|}
\hline GST(u/ l) & Liver & Kidney & Testes & Heart \\
\hline Group 1 & $5.30 \pm 0.08$ & $5.52 \pm 0.14$ & $4.85 \pm 0.30$ & $5.46 \pm 0.23$ \\
\hline Group 2 & $3.76 \pm 0.10^{*}$ & $3.55 \pm 0.21^{*}$ & $3.06 \pm 0.12^{*}$ & $3.16 \pm 0.27^{*}$ \\
\hline Group 3 & $8.46 \pm 0.30^{*}$ & $7.78 \pm 0.11^{*}$ & $6.38 \pm 0.14^{*}$ & $8.00 \pm 0.30^{*}$ \\
\hline Group 4 & $9.50 \pm 0.12^{*}$ & $12.65 \pm 0.12^{*}$ & $10.53 \pm 0.12^{*}$ & $11.41 \pm 0.13^{*}$ \\
\hline Group 5 & $4.18 \pm 0.11^{*}$ & $4.80 \pm 0.15^{*}$ & $3.56 \pm 0.12^{*}$ & $3.11 \pm 0.28^{*}$ \\
\hline Fvalue & 2821.499 & 3693.347 & 1933.444 & 1393.342 \\
\hline Pvalue & 0.001 & 0.001 & 0.001 & 0.001 \\
\hline
\end{tabular}

Table 8: Showing Mean \pm S.D of GST of Tissue Samples from Liver, Kidney, Testes and Heart of Nacl-Induced Hypertensive Male Wistar Rat for 0-8 Weeks Key: GST-Glutathione -S- Transferase. P -Value $<0.05$ Is Considered Statistically Significant. *=Shows Significant Difference When Compared With Group 1(Normal Group)

\begin{tabular}{|c|c|c|c|c|}
\hline CAT(u/ ml) & Liver & Kidney & Testes & Heart \\
\hline Group 1 & $43.33 \pm 1.86$ & $42.80 \pm 1.99$ & $28.70 \pm 0.77$ & $37.40 \pm 1.33$ \\
\hline Group 2 & $22.16 \pm 0.50^{*}$ & $21.30 \pm 0.67^{*}$ & $16.05 \pm 0.69^{*}$ & $29.88 \pm 0.82^{*}$ \\
\hline Group 3 & $46.57 \pm 0.62^{*}$ & $50.23 \pm 0.87^{*}$ & $32.90 \pm 0.97^{*}$ & $42.25 \pm 1.04^{*}$ \\
\hline Group 4 & $48.88 \pm 3.01^{*}$ & $53.13 \pm 1.56^{*}$ & $39.13 \pm 1.13^{*}$ & $46.81 \pm 0.86^{*}$ \\
\hline Group 7 & $42.50 \pm 1.37$ & $41.43 \pm 1.21^{*}$ & $27.28 \pm 0.90$ & $30.55 \pm 1.65$ \\
\hline Fvalue & 199.437 & 485.876 & 197.837 & 183.934 \\
\hline Pvalue & 0.001 & 0.001 & 0.001 & 0.001 \\
\hline
\end{tabular}

Table 9: Showing Mean \pm S.D of Catalase(CAT) of Tissue Samples from Liver, Kidney, Testes and

Heart of Nacl-Induced Hypertensive Male Wistar Rat for 0-8 Weeks

Key: CAT=Catalase. P -Value $<0.05$ Is Considered Statistically Significant

*=Shows Significant Difference When Compared With Group 1(Normal Group)

\section{Discussion}

In this study, induction of hypertension was achieved through $8 \% \mathrm{NaCl}$ in male wistar rats. This was in agreement with the work done by Rini et al, 2014.The results from the study showed a reduction in systolic blood pressure, diastolic blood pressure, mean BP, blood volume and heart rate in the group treated with $200 \mathrm{mg} / \mathrm{kgbwt}$ and $400 \mathrm{mg} / \mathrm{kgbwt}$ in a dose dependent manner. This reduction was also observed in the reference (lisinopril) group. Showing that reduction may be similar to the angiotensin converting enzyme inhibition mechanism seen in lisinopril in the control of blood pressure. Oxidative stress has been implicated as a factor that contributes to various forms of cell death as free radicals react with lipids causing peroxidation, resulting in the release of products such as malondialdehyde, hydrogen peroxide, hydroxyl radicals (Pompella et al., 1991).

The result from the study showed that hypertension significantly increased tissue level of malondialdehyde after induction. Also, significant decrease in tissue level of antioxidant enzymes such as SOD, catalase, Glutathione reductase and total antioxidant capacity were observed. These findings were in agreement with work done by Shitti, 2016, who observed a similar result although it was in aqueous leaf extract of Ocimum gratissimum. Oxidative stress was characterized by increased lipid peroxidation and altered enzymatic antioxidant system. Increase in MDA may result to oxidative damage to cell membranes, inhibition of several important enzymes, reduced cellular function and cell death. The reduction of antioxidant enzymes could be related to decreased synthesis or increased degradation of the antioxidant system by NaCl-induced oxidative stress. 
However, treatment with Vernonia amygdalina showed a reduction of MDA and elevation of antioxidant enzymes. The group given $400 \mathrm{mg} / \mathrm{kg}$ VA showed a significant reduction than the group given $200 \mathrm{mg} / \mathrm{kg}$. This shows that the reduction of MDA is dose dependent.Similarly, invivo evaluation of graded fresh leave extracts of Vernonia amygdalina on oxidative stress indicators in rats showed that the leaves have potentials to be valuable in reducing powers and free radical quenching (Iyawe and Azih 2015). Therefore, the phytochemical component of Vernonia amygdalina may potentiate its increased antioxidant activities in the treated group. The reduction in MDA was not observed in the reference (lisinopril) group. The group treated with the graded doses of the extract have the advantage of benefiting from the reduction of MDA and increased in antioxidant enzymes that helps to prevent the cells against free radical induced damages.

Glutathione, an important water-soluble antioxidant can directly neutralize reactive oxygen species such as lipid peroxides and also plays a major role in xenobiotic metabolism. Glutathione transferases show high activity with lipid peroxides. These enzymes are particularly higher in the liver. Catalase catalyses the decomposition of hydrogen peroxide to water and oxygen. SOD is an antioxidant that catalyses the dismutation of superoxide anion (O-). This anion could react with nitric oxide to produce peroxynitrite (ONOO-) which is a potent oxidant and nitrosating agent that can damage proteins, lipids and DNA (Di Naso et al., 2011). SOD converts superoxide radicals into hydrogen peroxide \& catalase converts $\mathrm{H}_{2} \mathrm{O}_{2}$ to $\mathrm{H}_{2} \mathrm{O}$ and oxygen.

In conclusion, supplementation of Vernonia amygdalina in hypertensive may be beneficial since it has an ameliorating effect in oxidative stress generated in hypertensive conditions.

\section{References}

i. Carretero, OA., Oparil, S. (2000). Essential hypertension. Part 1: definition and etiology. Circulation. 101 (3) :329-35.

ii. CDC. (2015). High blood pressure fact sheet.

iii. Di Naso, F.C., Simoes, D.A., Porawski, M., Marroni, N.A. (2011). Exogenous superoxide dismutase: action on liver oxidative stress in animals with streptozotocin-induced diabetes. Exp Diabetes Res, 754132.

iv. Dimeo F., Pagonas, N., Seibert, F., Arndit, R., Zidek, W., Westhof, T.H. (2012). Aerobic exercise reduces blood pressure in resistant hypertension. Hypertension. 60:653-658.

v. Gutteridge, J.M., Wilkins, S. (1982). Copper dependent hydroxyl radical damage to ascorbic acid; formation of thiobarbituric acid reactive products. FEBS letters.137: 327-330.

vi. Habig, W.H., Pabst, M.J., Jakoby, W.B. (1974). Glutathione S-transferase. The first enzymatic step in mercapturic acid formation. Journal of Biological Chemistry. 246: 7130-7139.

vii. He, F.J., Macgreger, G.A. (2007). Salt, blood pressure and cardiovascular diseases. Current Opinion in Cardiology. 22:298-305.

viii. Hersh, D.W., Bray, G.A. (2008). Weight loss and blood pressure control (pro). Hypertension. 51:1420-1425.

ix. Iyawe, H., Azih, M. (2015). In vivo evaluation of graded fresh leaves of vernonia amygdalina and Ocimum gratissimum on some oxidative stress indicators in rats. Biomedical Research and therapy.2 (7):333-338.

x. Lackland, D.T., Weber, M.A. (2015). Global burden of cardiovascular disease and stroke. Hypertension at the core. The Canadian journal of cardiology.31 (5): 569-71.

xi. Lau. D, Nattel S., kalman, J., Sanders, P. (2017). Modifiable Risk Factors and Atrial fibrillation. Circulation (review). 136(6): 583-96.

xii. Misra, H. P., Fridovich I.(1972). The role of antioxidation of epinephrine and a simple assay for superoxide dismutase. Journal of Biological Chemical. 247:3170.

xiii. Moore, T., Svetkey,.L., Appel, L., Bray, G., Volmer, W. (2001). The Dash diet for hypertension. New York. Simon and Schuster.

xiv. Naish, J., Court, D.S. (2014). Medical sciences (2ed).p.562.

xv. National Heart, Lung, and Blood institute (2015). How is high blood pressure treated?

xvi. Perez, V., Chang, E.T.(2014). Sodium-to-potassium ratio and blood pressure, hypertension, and Related factors. Advances in nutrition.5 (6): 712-741.

xvii. Pescatello, L.S., MacDonald, H.V., Lamberi, L., Johnson, B.T.(2015). Exercise for hypertension: A prescription update integrating Existing Recommendations with Emerging Research. Current Hypertension Reports.17(1): 87.

xviii. Pompella, A., Romani, A., Benditti, M. (1991). Comportilose of membrane protein thiols and lipid peroxidation of allyl alcohol hepodotoxicity. Priochempharmacol , 41: 1225-59.

xix. Poulter, N.R., Prabhakaran, D., Caul, F.M. (2015).Hypertension. Lancet 386 (9995): 801-12. 
xx. Rini, S., Elin,Y. S., Tommy, A., Joseph, I.S.(2014). The effect of coconut water (Cocos nucifera L.) and an isotonic drink on the change of heart rate frequency in the rats induced hypertension. Procedia chemistry 13.177-180.

xxi. Shittu, S.T., Oyeyemi,W.A., Lasisi, I.J., Shitti, S.A., Lawal, T.T., Olujobi, S.T.(2016). Aqueous leaf extract of Ocimum gratissimum improves hematological parameters in alloxan-induced diabetic rats via its antioxidant properties. International journal of applied basic medical Res. 6:96-100.

xxii. Sinha, A. K. (1972). Colorimeteric assay of catalase. Analytical Biochemistry. ` 47:389-394.

xxiii. Sung, K.H.(2014). Dietary salt intake and hypertension. Electrolytes and blood pressure.12 (1):7-18.

xxiv. World health organization. Raised blood pressure. Global Health Observatory (GHO) data. Archived from the original on 8 August 2016. 